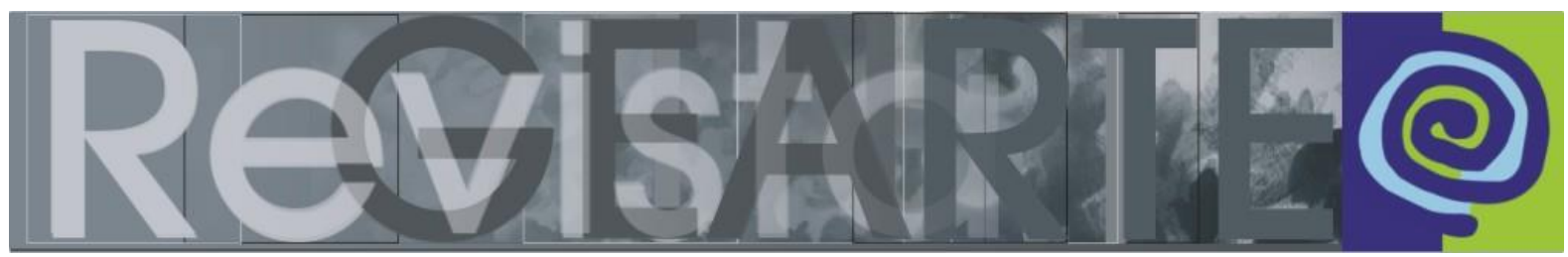

e-ISSN 2357-9854

\title{
Abordagem Triangular do Ensino das Artes e Culturas Visuais: uma teoria complexa em permanente construção para uma constante resposta ao contemporâneo
}

\author{
Maria Christina de Souza Lima Rizzi (Universidade \\ de São Paulo - USP, São Paulo/SP, Brasil) \\ Mauricio da Silva (Universidade de São Paulo — USP, São Paulo/SP, Brasil)
}

\begin{abstract}
RESUMO - Abordagem Triangular do Ensino das Artes e Culturas Visuais: uma teoria complexa em permanente construção para uma constante resposta ao contemporâneo - A contribuição da Abordagem Triangular para a transformação dos processos de ensino das artes e ao ensino das culturas visuais no Brasil e América Latina a partir do final da década de 1980 é incontestável. E mesmo sistematizada no final do século XX, observamos que a Abordagem vem sendo aprimorada tanto a partir das pesquisas que a observam na prática quanto a partir de pesquisas que procuram se aprofundar nos âmbitos teóricos e epistemológicos. Partindo das ideias de Ana Mae Barbosa, em sua sistematização, adequação terminológica, explicitação dos fundamentos e desdobramentos dos conceitos fundantes da Abordagem Triangular, caminhando pela observação de Rizzi sobre o seu caráter complexo, com a definição de Azevedo que a coloca como teoria, e suas decorrentes práxis Arteducativa e Virada Arteducativa e os apontamentos de Silva sobre a natureza transdisciplinar, caracterizando a Arte e a Educação como áreas de conhecimento/macroconceitos e a inter-relação destas como trans-áreas.
\end{abstract}

PALAVRAS-CHAVE

Abordagem Triangular do Ensino das Artes e Culturas Visuais. Complexidade. Epistemologia. Transdisciplinaridade.

ABSTRACT - Triangular approach on Art Education and Visual Cultures: a complex theory in permanent construction to a constant answer to the contemporary - The contribution of the Triangular Approach to the transformation of the processes of teaching the arts and teaching visual cultures in Brazil and Latin America since the end of the 1980s is undeniable. And even systematized at the end of the twentieth century, we observe that the Approach has been improved both from the researches that observe it in practice, and from research that seeks to deepen in the theoretical and epistemological spheres. Starting from the ideas of Ana Mae Barbosa, in its systematization, terminological adequacy, explicitation of the foundations and unfolding of the founding concepts of the Triangular Approach, walking through the observation of Rizzi on its complex character, with the definition of Azevedo that puts it like theory, and its resulting in Arteducativa and Virada Arteducativa praxis and Silva's notes on the transdisciplinary nature, characterizing Art and Education as areas of knowledge / macroconcepts and the interrelation of these as trans-areas.

\section{KEYWORDS}

Triangular Approach to Teaching Arts and Visual Cultures. Complexity. Epistemology. Transdisciplinarity. 
Homem nada sabe, mas é chamado a tudo conhecer. Hermes Trimegisto

É inconteste a influência e transformação positiva trazida pela Abordagem Triangular ao ensino das artes e ao ensino das culturas visuais a partir do final da década de 80 e início dos anos 90 do século XX em diante.

Como sabemos, essa Abordagem, configurada por Ana Mae Barbosa em seu livro A imagem no ensino da arte: anos 80 e novos tempos (2010), foi e tem sido aprimorada no decorrer do tempo. Passou, pelas mãos da própria autora, por adequação terminológica (BARBOSA, 1998), explicitação de seus fundamentos, desdobramentos de seus conceitos fundantes, abordagem teórico-política de temas contemporâneos e outras avaliações (BARBOSA, 2002). Esta abertura ao aprimoramento fez com que a Abordagem Triangular por vezes seja mal compreendida e sofra críticas, sendo algumas delas, no nosso entender, equivocadas.

No sentido de continuar o diálogo teórico entre os professores e pesquisadores que se debruçam sobre este assunto é que escrevemos este artigo. Temos a intenção de contribuir com o debate por meio de colaborações teóricas já de domínio público e de uma contribuição original oriunda de dissertação de mestrado defendida em 2016 no Programa de Pós-Graduação em Artes Visuais da Escola de Comunicações e Artes da USP (SILVA, 2016).

No caminhar do pensamento teórico sobre a Abordagem Triangular, em diálogo com a proposta de Ana Mae Barbosa, destacamos primeiramente uma das autoras deste texto, Christina Rizzi, na sequência, Fernando Antonio Gonçalves de Azevedo e Maurício da Silva, também um dos autores do presente texto. A escolha dos autores estudados foi feita baseada nas afinidades das inquietações a respeito desta abordagem.

A colaboração trazida por Christina Rizzi (1999) à compreensão da conceituação da Abordagem Triangular foi a leitura e interpretação desta no Paradigma da Complexidade sistematizado por Edgar Morin (1996). 
Estudando Morin foi possível compreender que a proposta epistemológica para o ensino das artes feita por Ana Mae não preconiza uma sequenciação de ações e conteúdos, mas uma imbricação destes.

Podemos, com pertinência, nos remetermos, para esta compreensão por meio de um dizer ancestral, expresso por Hermes Trismegisto no Caibalion (cerca de 1300 a.C.), na segunda de sete leis, a Lei de Correspondência: "O que está em cima é como o que está embaixo. O que está dentro é como o que está fora" (CAMAYSAR, 2002, cap. VIII)

Entendida desta forma há nas ações fazer, ler e contextualizar a presença de cada uma delas (com uma nuance de ênfase entre elas) e em cada área do saber que concorre para a construção de conhecimento em artes e culturas visuais a presença das outras áreas (variando em concentração).

\section{Diagrama 1 - A Abordagem Triangular do Ensino das Artes e Culturas Visuais e seus níveis de constituição}

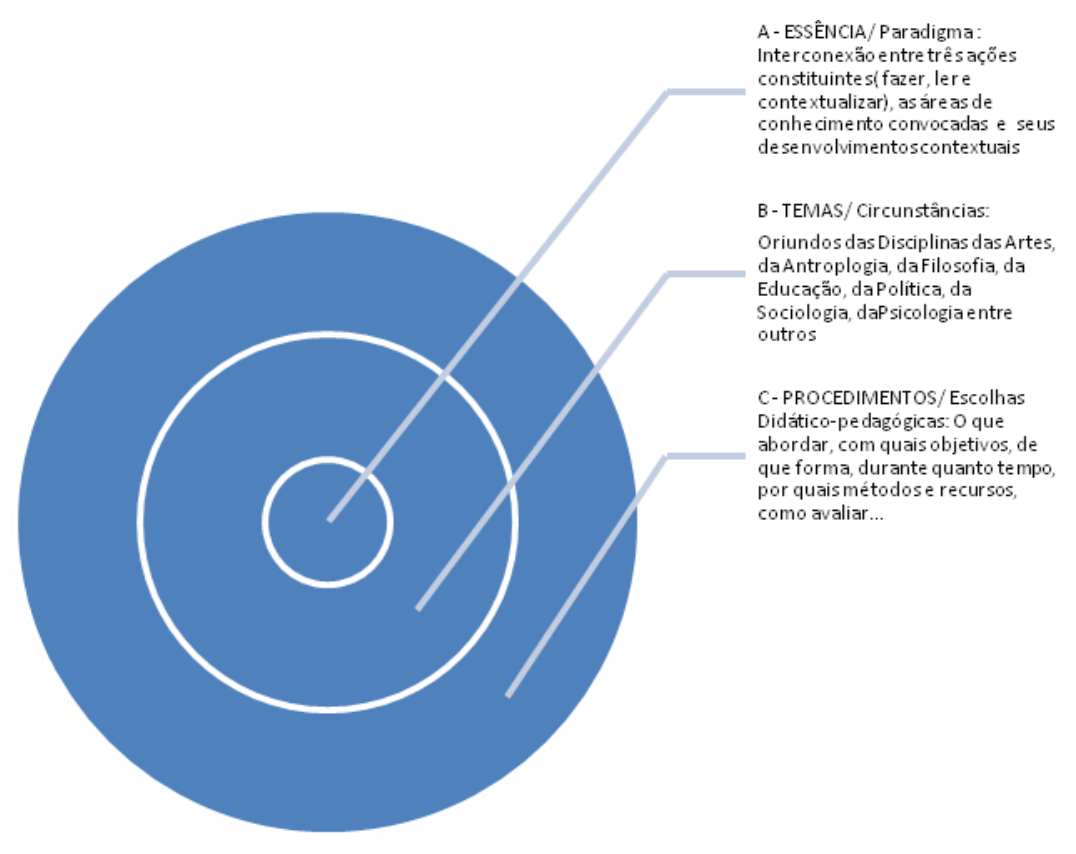

No cerne, em essência, a Abordagem Triangular é uma postura epistemológica do sujeito, dos sujeitos, face ao processo de construção de conhecimento.

Para se movimentar esta postura precisa de temas, conteúdos que são circunstanciados. Têm existência histórica - cultural - sociólogica-ideológica. São 
oriundos de escolhas teórico-político-pedagógicas e levam às ações constituintes da Abordagem (é uma via de dupla mão).

Para operar é preciso que se escolha, se crie procedimentos, por meio dos quais a proposta como um todo se realiza. Estes também são produtos das escolhas socioculturalmente enraizadas. Grosso modo podem ser procedimentos pluridisciplinares, multidisciplinares, interdisciplinares ou transdisciplinares, como apontaremos no decorrer do texto. No entanto, já adiantamos que a Abordagem Triangular das Artes e Culturas Visuais na sua plenitude é realizada na transdiciplinaridade, na vivência da complexidade de Morin.

O que temos identificado nas críticas feitas à Abordagem Triangular é que são críticas (equivocadas ou não) que se prendem aos aspectos móveis que constituem a Abordagem e não à sua dimensão essencial ou paradigmática. São críticas relativas a conteúdos, posturas ideológicas e/ou procedimentos. Isto no nosso entender não invalida a Abordagem Triangular como postura epistemológica de ensino e aprendizagem da arte; muito menos a supera.

Por já não ser considerada uma metodologia e sim uma Abordagem complexa, que é composta por sua essência, temas e procedimentos, a Abordagem Triangular do Ensino das Artes e Culturas Visuais se apresenta como orientação sistematizada por meio das ações decorrentes do Ler-Fazer-Contextualizar. A partir desta orientação sistematizada o educador/professor desenvolve seu método, respeitando o encaixe das relações educador-educando-espaço educativo- comunidade, objetivando serem essas relações mais horizontalizadas, buscando coerência ao contexto e ao conteúdo que pretende abordar.

Esse entendimento, que coloca a Abordagem Triangular em uma camada epistemológica superior ao de uma metodologia, levou Fernando Antonio Gonçalves de Azevedo a apontar a Abordagem Triangular do Ensino das Artes e Culturas Visuais como uma teoria de caráter complexo (AZEVEDO, 2016, p. 23), que apresenta caminhos, mas não dá as receitas de como fazer, indicando uma práxis e apresentando o desenho de uma Epistemologia da Arte e da Arte/Educação. 
Vale apontar que, por ser teoria de caráter complexo, teoria deve ser entendida pelo conceito de Morin (2008, p. 273) de teoria sistemizada ${ }_{1}$ ou seja, uma teoria que remeta à complexidade. Morin (2008) entende o conceito de sistema não como algo que se refira à totalidade, mas sim à complexidade. Se apenas aplicarmos diretamente a teoria geral dos sistemas às áreas que estudarmos, ela seria reducionista, pois levaria a área ao holismo. Morin considera que o holismo torna-se reducionista por redução ao todo. Assim uma teoria, para não se tornar reducionista em relação ao próprio campo, olhando apenas para si mesma e não para suas relações com as outras áreas, ou em relação ao holos, apenas olhando para o todo, deve ser uma teoria sistemizada, garantindo sua própria organização e conceitos, mas aberta às relações diversas, dinâmicas e complexas.

Uma teoria sistemizada, ou teoria de caráter complexo, deve ser aberta às relações construídas no campo que atua. É por essa abertura às dinâmicas próprias e amplas que Azevedo indica que a Abordagem Triangular do Ensino das Artes e Culturas Visuais é uma teoria inacabada e aberta, e por suas bases freirianas é dialógica. $\mathrm{O}$ fato de ser inacabada se destaca como qualidade a ser enaltecida, pois permite que arte/educadores/pesquisadores façam contribuições a todo momento.

A contribuição de Fernando Azevedo, ao refletir sobre o desenvolvimento teórico epistemológico da Abordagem Triangular, ao defini-la como teoria de caráter complexo, se dá também na transmutação dessa teoria em prática, ou seja, observa a sua aplicabilidade.

Azevedo apresenta assim a noção de práxis Arteducativa. A opção pela utilização da palavra práxis (2016, p.126) se faz por considerar que o termo prática é insuficiente para a ação do arte/educador que segue a perspectiva da Abordagem Triangular do Ensino das Artes e Culturas Visuais.

Assim como Ana Mae Barbosa, Azevedo orienta-se nas ideias de Paulo Freire (1987, p. 21), que na obra Pedagogia do Oprimido descreve a práxis como "a reflexão e ação dos homens sobre o mundo para transformá-lo". Assim a práxis freiriana não pode separar a ação/prática da reflexão/teoria. A práxis é a constante relação entre teoria e prática, que se alternam e se sobrepõem e se retroalimentam, levando cada 
vez mais a ação estar fundamentada, como também a teoria mais aproximada à realidade que pretende sistematizar.

$\mathrm{Na}$ definição de Azevedo (2016) a práxis Arteducativa remete ao ethos do arte/educador, ou seja, à identidade do grupo de educadores que trabalham na interrelação Arte/Educação, buscando

[...] enfatizar no contexto mais amplo da Educação o campo da Arte/Educação - o ethos do arte/educador - e a sua ação política de democratização dos saberes artísticos. Isto significa trazer para o âmbito dos processos de ensino e de aprendizagem a dimensão estética e artística como fundantes para aquilo que Freire chama de leitura de mundo (2016, p. 127).

Além disso, a práxis Arteducativa está diretamente relacionada à epistemologia da arte, por estudar os modos como se ensina e se aprende arte (RIZZI, 2012, p. 69), "mas é epistemologia situada histórica e socialmente, isto é, se materializa na estreita relação entre teoria do conhecimento com teoria do ser" (AZEVEDO, 2016, p. 128, grifos do autor). Essa conexão entre epistemologia e ontologia se faz no contexto do qual faz parte o processo arte/educativo que se referencia na Abordagem Triangular.

Para Azevedo a práxis Arteducativa problematiza "as questões contemporâneas da teoria e da prática (da práxis) do ensino e da aprendizagem em Arte, na perspectiva da Abordagem Triangular" (2016, p. 129), levando a uma virada arteducativa, ou seja, exige que o arte/educador também seja um pesquisador, um educador-pesquisador de sua própria atuação e do universo da arte, sendo que essa pesquisa além de acontecer também no âmbito do ler-fazer-contextualizar, é uma instância criadora.

Embora a imagem da teoria que indica a práxis, que por sua vez indica a metodologia desenvolvida pelo educador, possa parecer uma estrutura verticalizada e impositiva, na prática (e segundo os próprios referenciais teóricos) não é vertical. Essa estrutura seria melhor representada por camadas, sendo necessário entender por quais camadas estamos passando para que a inter-relação teoria/prática seja coerente. 
Neste sentido Mauricio da Silva faz uma leitura dessas camadas e apresenta como importante o entendimento das relações na camada mais superior a que se refere a Abordagem Triangular, ou seja, as relações entre Arte e Educação.

Como Christina Rizzi e Fernando Gonçalves Azevedo se valem das ideias de Edgar Morin para apresentar a Abordagem Triangular como conceito, teoria e prática complexas, o olhar para a relação da Arte com a Educação nessa teoria não pode ser reducionista. Deste modo Silva (2016) indica que essas áreas devem ser observadas a partir da concepção do macroconceito de Edgar Morin, pois sua observação se dá a partir do núcleo de ideias e das redes de relações conceituais que o estruturam. Para Morin (2008, p. 265) o macroconceito é formado por três componentes que são indissolúveis, pois para serem inteiros remetem uns aos outros: o sistema (unidade complexa), a interação (conjunto de relações, ações e retroações) e a organização (caráter constitutivo das interações, a forma).

O termo macroconceito se refere à noção de complexidade, indicando que algumas concepções conceituais se tornam tão ricas, elaboradas e profundas, que não possuem sentido completo sem serem pensadas por uma "constelação e solidariedade de outros conceitos" (MORIN, 2005, p. 72).

Como macroconceitos, as áreas de conhecimento Arte e Educação interagem entre si produzindo relações multidisciplinares, pluridisciplinares, interdisciplinares e transdisciplinares.

As relações multi e pluridisciplinares mantêm as separações bastante definidas entre as áreas, pois apresentam fronteiras bem delimitadas, como é apresentado no diagrama 2. 


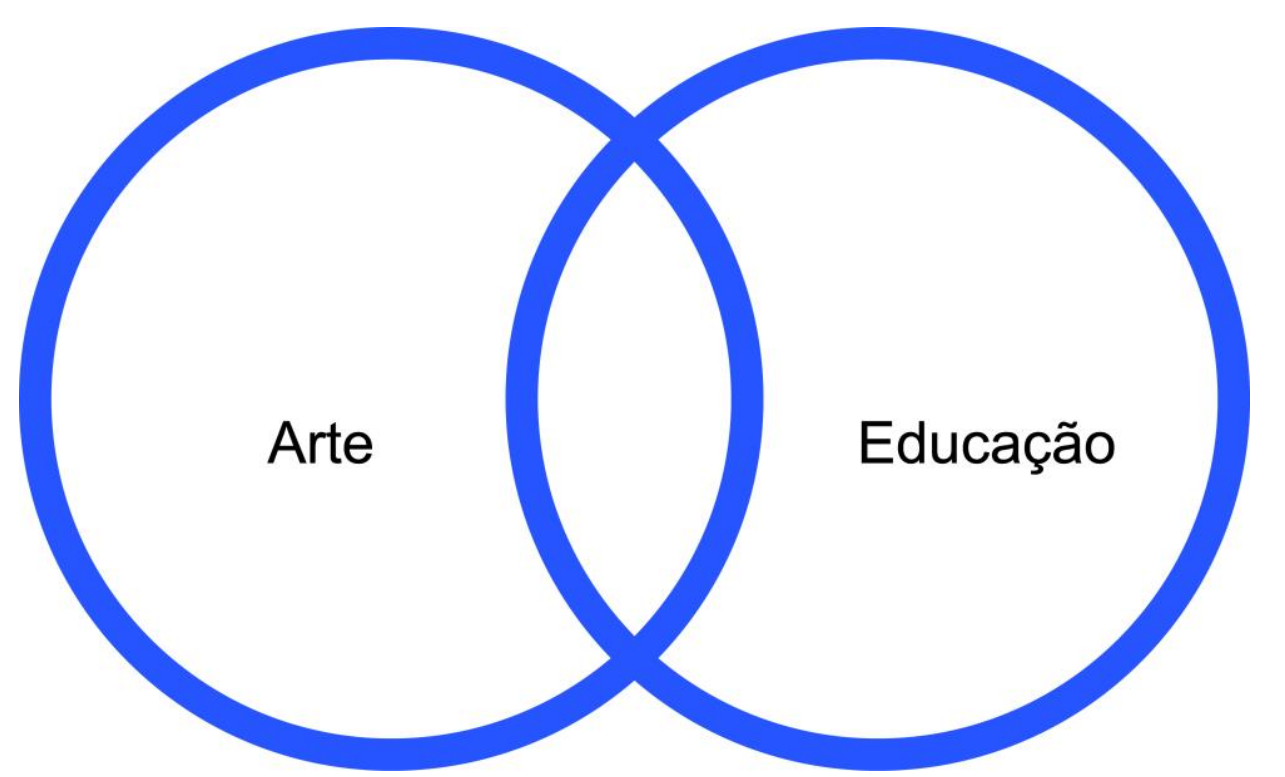

As relações interdisciplinares acontecem a partir das trocas entre as áreas, sendo um pouco mais difícil distinguir em sua prática qual é uma ou outra, mesmo que as áreas continuem existindo e possuindo fronteiras. O modelo que pode representar essas relações é o Nó Borromeano, neste caso de dois aros, pois apresenta as áreas formadas nas inter-relações e mostra que na retirada de uma das áreas todas as suas inter-relações deixam de existir, como apresenta o diagrama 3.

\section{Diagrama 3 - Relação Arte/Educação - Nó Borromeano}

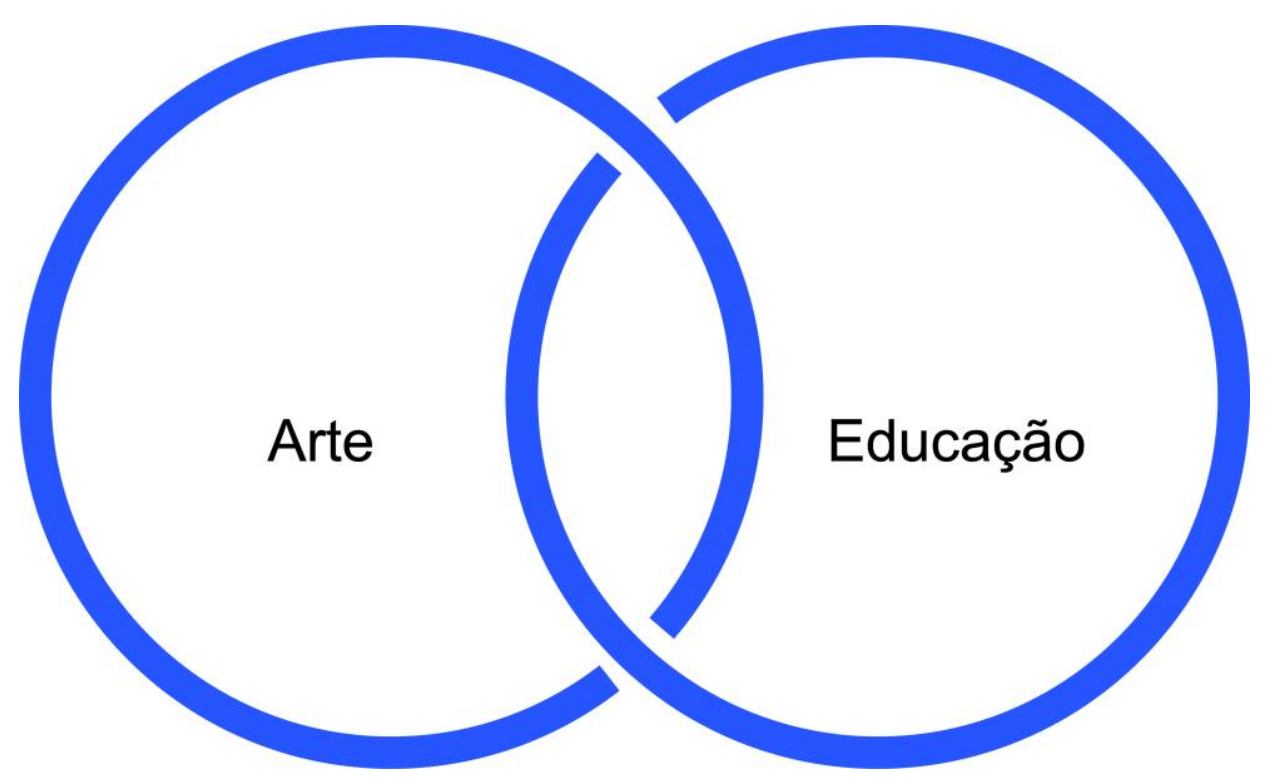


A perspectiva transdisciplinar, que dá plena vazão às potencialidades do macroconceito e da perspectiva da Abordagem Triangular do Ensino das Artes e Culturas Visuais, não delimita e não cria fronteiras, inter-relacionando as áreas a ponto não ser possível discernir uma das outras, conforme o diagrama 4.

\section{Diagrama 4 - Relação Arte/Educação - Órbitas}

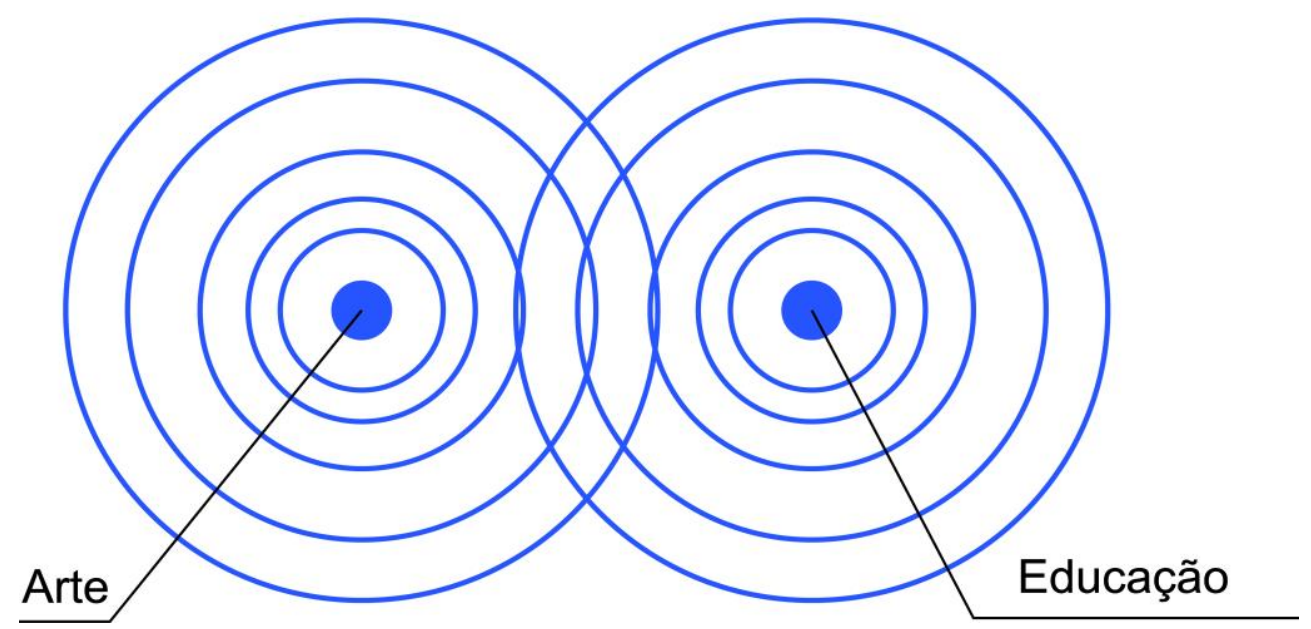

Imaginando em formato tridimensional e considerando que as linhas são permeáveis e influenciam umas às outras como ondas, a representação em órbitas apresenta as relações criadas entre Arte/Educação como trans-área (SILVA, 2016, p. 46), que não permitem ter seus componentes identificados, pois não é observável claramente o que é Educação, o que é Arte.

No modelo apresentado aqui, tão logo se consiga definir a organização que dá a sua forma, há reverberação e mistura com o outro macroconceito, a trans-área, sendo que o próprio núcleo do macroconceito/área não é maciço, porque é formado por um conjunto de ideias e procedimentos que se interligam e inter-relacionam.

A trans-área Arte/Educação pode ser pode ser observada, explicada e posta em prática por diferentes perspectivas, ou paradigmas, que se referem diretamente ao seu contexto sociopolítico-econômico-cultural. Considerando o contexto latinoamericano temos a perspectiva da Abordagem Triangular do Ensino das Artes e Culturas Visuais. As perspectivas estadunidenses (DBAE) e europeias (Critical Studies) têm a tendência de dividir o processo de crítica, produção e estudos sobre a 
História da Arte em disciplinas próprias. O Ler-Fazer-Contextualizar transforma o processo arte/educativo em transdisciplinar.

Nesse sentido, podemos entender a Abordagem Triangular como paradigma/teoria da trans-área Arte/Educação, isso porque a Abordagem Triangular, em sua potencialidade, indica ações, reflexões e atividades que de caráter transdisciplinares. A Abordagem Triangular não é pluri, multi ou inter, é transdisciplinar, assim entende a inter-relação Arte/Educação como transdisciplinar também.

É nesse caminho de reflexão teórica, considerando Ana Mae Barbosa, Christina Rizzi, Fernando Azevedo e Mauricio da Silva (entre outros), que podemos entender o contexto de avanço nas reflexões teóricas. A Abordagem Triangular se mantém viva, pois, em sua sistematização inicial já permitia uma abertura para aprofundamentos e desenvolvimentos. As pesquisas epistemológicas assim vão ampliando a visão e confirmando a contemporaneidade da Abordagem Triangular, que, ao ser revista, se adequa às novas ferramentas, hábitos, modos de fazer e conteúdos.

É por este caráter teórico, aberto, complexo, transdisciplinar e contemporâneo, de identidade latino-americana que propostas como a da e-Abordagem Triangular de Fernanda Pereira da Cunha (2013), que aponta a preocupação do lidar com as obras de arte e conteúdos digitais no ensino das artes; ou da formação de professores em artes visuais e a Educação a Distância, que considera a Abordagem Triangular como via de relações e produção de conhecimento coerente com o olhar integral que o professor deve possuir, de Jurema Sampaio (2014), também são importantíssimas para provar que se trata de um paradigma/teoria não preso à sua data de nascimento.

\section{Referências}

AZEVEDO, Fernando Antônio Gonçalves de. A Abordagem Triangular no ensino das artes como teoria e a pesquisa como experiência criadora. Jaboatão dos Guararapes: SESC, 2016.

BARBOSA, Ana Mae. Tópicos utópicos. Belo Horizonte: Ed. C/Arte, 1998.

BARBOSA, Ana Mae (Org.). Inquietações e mudanças no ensino da Arte. São Paulo: Cortez, 2002.

BARBOSA. Ana Mae. A imagem no ensino da arte: anos 1980 e novos tempos. 8. ed. São Paulo: Perspectiva, 2010. 
CAMAYSAR, Rosabis. O Caibalion: estudo da filosofia hermética do antigo Egito e da Grécia por três iniciados. São Paulo: Editora Pensamento-Cultrix, 2002.

CUNHA, Fernanda Pereira da. E-Arte Educação: educação digital crítica. São Paulo: Annablume, 2013.

MORIN, Edgar. O problema epistemológico da complexidade. Mem Martins, Portugal: Publicações Europa-América, 1996.

MORIN, Edgar. Introdução ao pensamento complexo. Porto Alegre: Ed. Sulina, 2005.

RIZZI, Maria Christina de Souza Lima. Olho vivo: Arte-Educação na exposição Labirinto da Moda: uma aventura infantil. 1999. Tese (Doutorado em Artes Visuais) - Escola de Comunicações e Artes, Universidade de São Paulo, 1999.

RIZZI, Maria Christina de Souza Lima. Caminhos metodológicos. In. BARBOSA, Ana Mae (Org.). Inquietações e mudanças no ensino da arte. São Paulo: Cortez, 2012, p. 69-77.

SAMPAIO, Jurema Luzia de Freitas. $O$ que se ensina e o que se aprende nas licenciaturas em artes visuais a distância? 2014. Tese (Doutorado em Artes Visuais) - Escola de Comunicações e Artes, Universidade de São Paulo, 2014.

SILVA, Mauricio da. A contribuição da Abordagem Triangular do Ensino das Artes e Culturas Visuais para o desenvolvimento da epistemologia da Educomunicação. 2016. Dissertação (Mestrado em Artes Visuais) - Escola de Comunicações e Artes, Universidade de São Paulo, 2016. Disponível em: <http://www.teses.usp.br/teses/disponiveis/27/27160/tde-03022017-163215/pt-br.php>. Acesso em: 10 de mar. 2017.

\section{Maria Christina de Souza Lima Rizzi}

Possui graduação em Educação Artística Artes Cênicas pela Universidade de São Paulo (1980), mestrado em Artes pela Universidade de São Paulo (1990) e doutorado em Artes pela Universidade de São Paulo (2000). Foi educadora nos seguintes museus: Pinacoteca do Estado e Museu da Casa Brasileira. Foi docente dos seguintes museus da USP: Museu de Arte Contemporânea, Museu de Arqueologia e Etnologia e vice-diretora do Museu de Ciências. Atualmente é professora doutora exercendo suas atividades no Departamento de Artes Plásticas da Escola de Comunicações e Artes da Universidade de São Paulo, onde leciona na Graduação e no Programa de Pós-Graduação em Artes Visuais (Conceito CAPES 6). Orienta mestrado e doutorado.

E-mail: rizzi.christina@gmail.com

Currículo: http://lattes.cnpq.br/0743565381235239

\section{Maurício da Silva}

Atua como Fotógrafo, Arte/educador e Educomunicador. É doutorando e mestre (2016) em Artes Visuais pelo Programa de Pós-Graduação em Artes Visuais da ECA/USP (conceito CAPES 6), na área de pesquisa "Teoria, Ensino e Aprendizagem da Arte, linha de pesquisa "Fundamentos do Ensino e Aprendizagem da Arte". Licenciado em Educomunicação pela ECA-USP (2016). Possui especialização em Mídias na Educação pelo MEC, na oferta realizada pela parceria UFPE-NCE/USP (2013). Também graduado em Comunicação Social - habilitação em Rádio e TV - pela Universidade São Judas Tadeu (2002).

E-mail: mauriciovirgulino@gmail.com

Recebido em 15 de março de 2017 Aceito em 18 de junho de 2017 